\title{
RÁDIO MESMICE: O descontentamento com a programação das rádios como impulso para a prática da pirataria musical (1980-1981)
} RADIO SAMENESS: Discontent with radio programming as an
impetus for the practice of musical piracy (1980-1981]

Enio Everton A. VIEIRA ${ }^{1}$

Universidade Presbiteriana Mackenzie de São Paulo | Brasil

\begin{abstract}
Resumo
Este artigo tem como objetivo elucidar os problemas criados pelo desenvolvimento das tecnologias de fitas e reprodutores cassete nos hábitos de consumo de música no fim da década de 1970 e início de 1980, durante a crise da indústria fonográfica. Mídias especializadas da época culpabilizavam as tecnologias cassete, ignorando fatores econômicos ou a postura conservadora das gravadoras. As rádios insistiam em uma programação repetitiva para ouvintes que buscavam diversidade. Nos basearemos em escritos de Peter Burke, Marcia Tosta Dias, Paul Friedlander, Marcos Napolitano, Walter Benjamin e Renato Ortiz, em edições publicadas entre 1979 e 1981 da revista SOMTRÊS.

\section{Palavras-chave}

História do rádio; fita cassete; pirataria musical; consumo; indústria fonográfica.

\section{Abstract}

This article aims to elucidate the problems created by the development of tape and cassette player technologies in the habits of music consumption in the late 1970 s and early 1980s, during the crisis of the music industry. Specialized media of the time blamed cassette technologies, ignoring economic factors or the conservative stance of record companies. The radio stations insisted on a repetitive program for listeners looking for diversity. We will supported by the writings of Peter Burke, Marcia Tosta Dias, Paul Friedlander, Marcos Napolitano, Walter Benjamin and Renato Ortiz, in editions published between 1979 and 1981 of SOMTRÊS magazine.

Keywords

History of radio; cassette tape; musical piracy; consumption; recording industry.
\end{abstract}

RECEBIDO EM 02 DE MARÇO DE 2020

ACEITO EM 11 DE MAIO DE 2020

1 Mestre pelo programa interdisciplinar em "Educação, Arte e História da Cultura" pela Universidade Presbiteriana Mackenzie de São Paulo. Graduado em História pela Universidade Nove de Julho (2014), pós-graduação lato senso em educação pela PUC (2017). Contato: teacherenio@gmail.com

João Pessoa - Brasil | ANO 7 VOL.7 N.1 | JAN./JUN. 2020 | p. 434-453 
Utilizando de reportagens e cartas dos leitores de SOMTRÊS, buscaremos neste trabalho compreender até que ponto as facilidades promovidas pela tecnologia cassete podem ser responsabilizadas pela crise da indústria musical ocorrida no início dos anos 1980. Pretendemos demonstrar como a falta de diversidade nas programações radiofônicas e nos catálogos das gravadoras acabavam por impulsionar as práticas de gravação caseira, pois os fãs de música procuravam ouvir novos artistas, cenário este pouco compreendido pelas rádios e gravadoras do período.

Iremos comparar tais cartas e reportagens citadas com a bibliografia historiográfica especializada no período, nos apoiando em autores como Renato Ortiz, Marcos Napolitano e Peter Burke. No que diz respeito à bibliografia especializada em música, utilizamos nomes como Paul Friedlander e Marcia Tosta Dias. Ao refletirmos acerca do caráter técnico da reprodução cassete, comparamos essa tecnologia aos escritos de Walter Benjamin e suas reflexões sobre a reprodutibilidade técnica da arte.

\section{Revista SOMTRÊS ${ }^{3}$}

Se auto intitulando a primeira revista de som e música do Brasil, SOMTRÊS foi inicialmente publicada em janeiro de 1979, sendo extinta em janeiro de 1989, totalizando 121 edições. Seu intuito era oferecer uma alternativa de informação aos chamados "audiófilos" (fãs de música e novidades em equipamentos de som) às publicações importadas que, além de custarem preços exorbitantes, exigiam o conhecimento de uma língua estrangeira - normalmente 0 inglês - e chegavam às bancas brasileiras com grande defasagem no que diz respeito aos lançamentos dos equipamentos de som e sua disponibilidade no mercado. Era "uma publicação brasileira, sem sotaque, para quem gosta da melhor música e exige o melhor som"4 ${ }^{\prime \prime}$. Todas

\footnotetext{
${ }^{3}$ A revista sempre escrevia seu próprio nome com letras maiúsculas. Respeitaremos tal grafia neste trabalho.

${ }^{4}$ KUBRUSLY, Maurício. Editorial. Revista SOMTRÊS, São Paulo, n. 01, jan. 1979, p. 05.
}

João Pessoa - Brasil | ANO 7 VOL.7 N.1 | JAN./JUN. 2020 | p. 434-453 
precariedade habitacional etc. (MELLO e NOVAIS, 1998, pp. 625626).

Entretanto, SOMTRÊS não era uma revista direcionada aos trabalhadores das classes mais baixas. Dirigida aos audiófilos, o jornalista Carlos Barradas da Silva define o público alvo da revista como pessoas que dedicam interesse "aos assuntos de som, com o objetivo de ouvir música gravada em ótimas condições" ${ }^{\prime \prime}$. Outras considerações que seguem na mesma matéria falam da importância de uma sala bem preparada acusticamente, de se ouvir boas gravações, na medida do possível, a não ser no caso de gravações antigas, pois neste caso o audiófilo deve buscar obter equipamentos que amenizem a precariedade da gravação original. Em outras palavras, uma família apertada em uma habitação de um ou dois cômodos não estaria apta para fazer parte do clube dos audiófilos. SOMTRÊS fazia parte, portanto, do conjunto de jornais e revistas que tiveram sua expansão no pós 64 "ancorada no crescimento da nova classe média, que tem renda suficiente para comprálos" (MELLO e NOVAIS, 1998, p. 639).

A crise econômica que se avizinhava é contraditória ao momento da industrialização que Ortiz (2003), Mello e Novais (1998) chamam de inserção forçada ao "Capitalismo Tardio", promovida pelos governantes militares nos anos entre os anos de 1964 e 1985. Na década de 1970 ocorrera o "Milagre Brasileiro", no qual o país passou por "um crescimento contínuo, ao longo do início da década de 1970, com taxas anuais em torno de 11\%" (SILVA, 2013, p. 260). Ao lado de tal crescimento, Marcos Napolitano (2014) aponta que os meios de comunicação e a indústria da cultura conheceram um crescimento até então sem precedentes na história do Brasil.

Com o crescimento econômico, os bens culturais passaram a ser consumidos em escala industrial: telenovelas, noticiários, coleções de livros e fascículos sobre temas diversos, revistas [...] demonstravam a nova tendência industrial e "massiva" do consumo cultural, que se consolidaria de vez na segunda metade da década

${ }^{6}$ SILVA, Carlos Barradas da. A Questão dos Princípios. Revista SOMTRÊS, São Paulo, n. 1, jan.1979, p. 08.

João Pessoa - Brasil | ANO 7 VOL.7 N.1 | JAN./JUN. 2020 | p. 434-453 


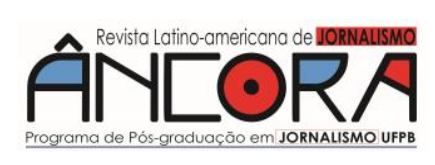

Enio Everton A. VIEIRA

de 1970. Dessa maneira, via bancas de jornal e televisão, a cultura escrita chegava aos segmentos mais pobres da população sobretudo operários qualificados, pequenos funcionários públicos e classe média baixa, como um todo. (NAPOLITANO, 2014, p. 82).

Devemos lembrar de outros fatores que interferiram nos preços dos produtos fonográficos, como, por exemplo, a crise mundial do petróleo ${ }^{7}$, matéria prima dos discos de vinil e das fitas cassete. A crise do petróleo acabara com o "Milagre Brasileiro", e demonstrara a fragilidade e a dependência do dinamismo econômico brasileiro em relação ao mercado externo. Veremos agora como todos os fatores até agora listados influenciaram o modo dos audiófilos consumirem sua música.

\section{A falta de diversidade das rádios}

Abrimos esse trabalho com a carta de José Bonifácio, que não era o único audiófilo que reclamava da programação repetitiva das rádios. Muitos outros leitores de SOMTRÊS efetuavam suas gravações direto das transmissões radiofônicas, graças às facilidades promovidas pela popularização das tecnologias cassete, e a superioridade técnica da transmissão em FM. Eduardo de Mattos se lamenta da qualidade da programação da Transamérica de Brasília, que além de só tocar músicas de discoteca, soul e estrangeiras, "não são tocadas até o final, embora não cheguem a 4 minutos"8. José Carlos compara as rádios nacionais com as estrangeiras, atribuindo uma nota três para as nacionais, enquanto dá nota dez para emissoras, americanas, alemãs, canadenses e uruguaias, registrando que "enquanto a programação não mudar, continuarei a ouvir as fitas que recebo do Exterior"' ${ }^{\prime \prime}$. Thrasivoulous Courcourpoulos critica o fato de várias FMs de São Paulo fazerem "superposições acidentais de músicas e partes faladas em mesmo nível sonoro,

${ }^{7}$ Crise iniciada em outubro 1973, quando Arábia Saudita, Irã, Iraque, Kuwait e Venezuela, países membros da Organização dos Países Exportadores de Petróleo (a Opep), decidiram aumentar o preço do óleo em "400\% em cinco meses (até março de 1974), com um novo aumento de 100\% na conferência de Teerã em 23 de dezembro desse ano". (COGGIOLA, 2008, p. 51)

8 MATTOS, Eduardo de. Cartas. Revista SOMTRÊS, São Paulo, n. 36, dez. 1981, p. 05.

${ }^{9}$ SILVA, José Carlos da. Cartas. Revista SOMTRÊS, São Paulo, n. 24, dez. 1980, p. 04. 
sem falar das mixagens malfeitas, comuns a todas também"10, se mostrando irritado de não pode ouvir suas músicas sem interferências sonoras. J.L. Rhoden demanda maior variedade nas programações, pois "acontece até de se encontrar, ao mesmo tempo, duas emissoras tocando a mesma música, no mesmo horário. Isso não acontece só com a MPB, mas também com a música pop internacional" ${ }^{\prime 11}$. Temos ainda a carta assinada pelo trio Paulo de Carvalho, Paulo Roberto e Carlos Tupinambá, que solicitam por via de SOMTRÊS um contato com a Rádio Nacional, para que voltem a passar o programa "Memória Nacional", para que pudessem "gravar, novamente, os lançamentos de longplays nacionais" 12 .

Essas são apenas algumas das cartas que apresentam reclamações semelhantes no que concerne à qualidade das rádios, seja no quesito programação ou pela má capacidade técnica das transmissões. Considerando os fatores econômicos, como o esgotamento do Milagre Brasileiro e alta inflação do período, não é de se estranhar que os audiófilos buscavam, cada vez mais, efetuar suas gravações das rádios, economizando na compra de discos. Segundo a tese de Alexandre Gouvêa Ladeira (2013), o fator econômico é, de fato, decisivo na aquisição de produtos tidos como piratas, e ao gravar as novidades musicais direto das rádios, os audiófilos faziam uma escolha consciente de sua aquisição.

É recorrente do senso comum atrelar o consumo de pirataria à questões de cunho meramente econômico, e nesse ponto não se pode dizer deste um raciocínio totalmente equivocado. De fato [...] os preços cobrados por determinados artigos tornam inviável a obtenção do bem chamado original, num indicativo de que o consumidor, antes de ser um sujeito passivo e que consome sem maiores reflexões ou sem levar em consideração as possíveis consequências de seus atos, é um ente dotado de uma racionalidade que interfere, de modo decisivo, em suas práticas aquisitivas. (LADEIRA, 2013, pp. 154-155).

${ }^{10}$ COURCOURPOULOS, Thrasivoulous. Cartas. Revista SOMTRÊS, São Paulo, n. 24, dez. 1980, p. 06.

${ }^{11}$ RHODEN, J.L. Cartas. Revista SOMTRÊS, São Paulo, n. 20, ago. 1980, p. 08.

12 CARVAlHO, Paulo de; TUPINAMBÁ, Carlos; VIEIRA, Paulo Roberto. Cartas. Revista SOMTRÊS, São Paulo, n. 19, jul. 1980, p. 06

João Pessoa - Brasil | ANO 7 VOL.7 N.1 | JAN./JUN. 2020 | p. 434-453 
Dos 100 títulos postos à venda na quase totalidade dos pontos, cerca de metade é tomada por música estrangeira, imposta pela divulgação em rádio \& tevê; 30 são discos promovidos pela televisão (trilhas de novelas e outras coletâneas); e 20 "são produtos dos 15 bilionários da música popular brasileira" (Roberto Carlos, Maria Bethânia, Rita Lee, etc.). E a música do Brasil - que pena... coitadinha - é muito maior do que isso que as lojas (não) oferecem, as rádios (não) tocam, as gravadoras (não) gravam e as tevês (não) mostram. ${ }^{15}$

Em um momento de alta dos preços, e conscientes que os álbuns teriam uma ou duas canções de trabalho de melhor qualidade, os ouvintes de música preferiam fazer uma escolha consciente em obter apenas as canções que lhes interessavam, gravando-as por meio das rádios. Chegou-se ao ponto de se comercializar essas fitas abertamente de duas maneiras: a pirataria em massa, que buscava se passar por um produto legítimo, e a pirataria caseira, feita em pequena escala, que se dava entre os fãs de música e era promovida, ora direta, ora indiretamente, pela revista SOMTRÊS, através de um mercado informal impulsionado pelos anúncios da seção Free-Shop. Esse é tópico de nosso próximo segmento.

\section{O mercado informal de SOMTRÊS}

A pirataria musical era preocupação constante nas páginas de SOMTRÊS, sendo condenada mas, nunca, de fato, reprimida. Sem dúvida, há matérias que acusam a pirataria enquanto forma de crime organizado, caindo na definição de pirataria como falsificação de um produto para obtenção de grandes lucros, apontando o problema de se vender música "sem pagar a autores ou produtores direito algum. E nem impostos"16. Uma matéria de abril de 1981 descreve como os piratas atuavam, sobretudo, em pontos de vendas em estradas, sendo a rodovia que liga Campinas a Brasília conhecida nos anos de 1980/1981 como a "estrada da pirataria". Os grandes centros urbanos como

${ }^{15}$ KUBRUSLY, Maurício. A herança de um brasileiro. Revista SOMTRÊS, São Paulo, n. 28, abr. de 1981, p. 98.

${ }_{16}$ BAHIANA, Ana Maria. Os piratas do som são ainda mais organizados. Revista SOMTRÊS, São Paulo, n. 28, abr. 1981, p. 57.

João Pessoa - Brasil | ANO 7 VOL.7 N.1 | JAN./JUN. 2020 | p. 434-453 


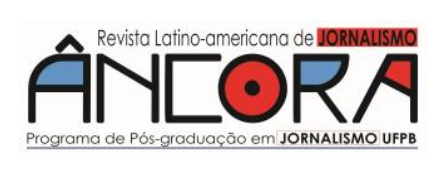

Enio Everton A. VIEIRA

São Paulo, Belo Horizonte e a Baixada Fluminense estavam entre os locais campeões de vendas de fitas falsificadas, e estimativas da Associação Brasileira de Produtores de Discos eram de quatro milhões de fitas piratas por ano, o que representava metade do mercado oficial de fitas cassete ${ }^{17}$.

A matéria dá algumas dicas de como saber se a fita gravada era falsa ou não. O consumidor deveria ficar atento na qualidade da foto de capa, se as cores não estavam desbotadas e tremidas, e se o rótulo não estava com suas bordas soltando. Isso tudo, claro, "falando da pirataria mais óbvia, que não procura ocultar sua condição de cópia, e que vem com rótulos datilografados, sem seguir a capa original"18. Com razão a matéria esclarece que um consumidor que compra inadvertidamente uma fita pirata, que busca se passar por original, está sendo lesado. Contudo, um consumidor que compra uma fita com um rótulo datilografado, se sentiria ele lesado? Estaria tal consumidor esperando que uma fita claramente feita em casa fosse, de alguma maneira, um produto original?

O público consumidor muitas vezes tem pouco interesse em adquirir um disco se o que lhe interessa é apenas uma ou duas músicas. Em geral, o perfil desse tipo de comprador é o de quem tem preferência pelos sucessos, os hits do momento. Dos anos 1970 a meados dos 1990, não apenas as fábricas clandestinas atendiam a essa demanda específica. As lojas de discos gravavam fitas cassete com o repertório selecionado pelos próprios clientes: as coletâneas podiam ser de músicas do mesmo ou de diversos gêneros e de um ou vários artistas, nem sempre seguindo apenas a lógica dos grandes sucessos, uma vez que a seleção era de caráter mais pessoal. Concorrer com os piratas nesse quesito era praticamente impossível (SANTOS, 2010, p. 87).

Os anúncios de SOMTRÊS nos indicam que existiam muitos aficionados por música pouco preocupados com os detalhes técnicos, estéticos e de mídia na qual apreciavam suas canções favoritas. Na edição de setembro de 1979, o leitor Paulo anunciava que queria comprar discos em bom de estado de artistas como Tony Bennet, Paul Weston, Jackie Gleason, entre outros, mas

17 BAHIANA, Ana Maria. Os piratas do som são ainda mais organizados. Revista SOMTRÊS, São Paulo, $n$. 28, abr. 1981, p. 57.

${ }_{18}$ BAHIANA, Ana Maria. Os piratas do som são ainda mais organizados. Revista SOMTRÊS, São Paulo, n. 28, abr. 1981, p. 58. 
comunica que "podem ser cópias em fita cassete"19. Isso sugere um desapego ao formato físico da música.

Paulo não era, de modo algum, um caso isolado entre os anúncios de compra e venda de SOMTRÊS. Em números mais precisos, somente no ano de 1980, foram publicados um total de 395 anúncios de compra, venda, e/ou troca de gravações, sendo que desses anúncios, 41 buscavam gravações em fita (10,38\% do total publicado). Em 1981, de 549 anúncios, 48 buscavam gravações em fita, representando $8,74 \%$ dos anúncios. O número de pessoas que buscavam gravações não é, de forma alguma, negligenciável, sugerindo que o formato da mídia musical não era uma exigência para muitos dos consumidores de música.

SOMTRÊS dizia em suas páginas que condenava a prática da cópia caseira, mas, em nenhum momento nas edições aqui consultadas, reprimiu seus leitores de praticá-la. A revista fazia "vistas grossas" para publicações como a de Paulo, e buscava se isentar da responsabilidade de publicar anúncios que abertamente falavam de pirataria e/ou gravações caseiras, sempre avisando seus leitores que eles poderiam "anunciar qualquer coisa, menos cópias em fitas de discos que ainda estejam à venda no Brasil"20. Tais dizeres aparecem em 13 das 24 edições utilizadas para levantar esses dados.

Tamanha movimentação de compra, venda e troca de discos, e outros itens, pode nos parecer estranha em época de aguçada crise econômica, ainda mais considerando uma forma de entretenimento descrita pelo editora chefe de SOMTRÊS como algo "supérfluo"21. A grande movimentação promovida no comércio paralelo dos anúncios de Free-Shop estava, sobretudo, na compra e venda de discos. Em 1980, momento no qual a inflação chegou aos $110,2 \% 22$,

\footnotetext{
19 Paulo.Free-Shop. Revista SOMTRÊS, São Paulo, n. 09, set. 1979, p. 64.

20 Free-Shop. Revista SOMTRÊS, São Paulo, n. 36, dez. 1981, p. 33. Anúncios coibindo a cópia de discos aparecem, entretanto, nas edições de 17, 20, 21, 22, 23, 25, 27, 28, 29, 30, 31, 32, 33, 34, 35 e 36 . As edições de número 20, 21, 22 e 25 são as únicas que utilizam o termo fita pirata/pirataria.

${ }^{21}$ KUBRUSLY, Maurício. Inédito: Os números do negócio dos discos. Revista SOMTRÊS, São Paulo, n. 03, mar. 1979, p. 97.

${ }^{22}$ Segundo FAUSTO, 2012, p. 428
}

João Pessoa - Brasil | ANO 7 VOL.7 N.1 | JAN./JUN. 2020 | p. 434-453 
da sociedade consumista, pois, diferentemente de um disco, no qual suas faixas não podem ser alteradas ou mudadas de ordem, uma gravação em fita poderia ser completamente alterada, uma vez que o ouvinte não quisesse mais desfrutar do conjunto de músicas da gravação. Tal facilidade de uso coincide com a ideia de que "a vida de consumo não pode ser outra coisa senão uma vida de aprendizado rápido, mas também precisa ser uma vida de esquecimento veloz" (BAUMAN, 2008, p. 124).

Outro dado importante de destacarmos nos anúncios de SOMTRÊS é que os artistas mais buscados, em sua vasta maioria, são artistas estrangeiros, e álbuns que não haviam sido lançados em território nacional, (outra falha de atendimento da demanda pelas gravadoras). Em 1980, 31,4\% dos anúncios buscavam exclusivamente artistas estrangeiros, enquanto 7,09\% queriam adquirir discos de artistas brasileiros. No ano seguinte, os números não sofrem grandes alterações, com o número de leitores buscando por artistas de outros países em $29,33 \%$, contra $7,83 \%$ de audiófilos procurando por discos nacionais. Os leitores que procuravam por álbuns nacionais buscavam sempre álbuns fora de catálogo, enquanto os que queriam gravações de artistas estrangeiros procuravam álbuns que não haviam sido lançados no Brasil. Isso nos indica como as gravadoras não compreendiam seu próprio público, tirando de catálogo e/ou deixando de lançar álbuns com potencial de venda.

Free-Shop, o "primeiro e único mercado livre de equipamentos e discos do Brasil"26 funcionava gratuitamente, com os leitores enviando suas cartas anunciando a compra, venda e/ou troca dos mais variados acessórios musicais, amplificadores, caixas acústicas, gravadores, receptores, sintonizadores, cabos, fones de ouvido, mini-estéreos, aparelhos conjugados, vídeos, bandas procurando músicos, letristas e/ou compositores oferecendo seus serviços, fãs solitários buscando conversar com outros aficionados, letras de música, partituras, revistas importadas, livros de biografias musicais, e, principalmente,

${ }^{26}$ Auto-descrição presente em 13 das 24 edições consultadas.

João Pessoa - Brasil | ANO 7 VOL.7 N.1 | JAN./JUN. 2020 | p. 434-453 
mais acessíveis, se a matéria-prima utilizada na confecção do disco e da capa, basicamente, continua a mesma?27

Um dos colaboradores de SOMTRÊS responde a Arthur, dizendo que em breve a revista lançaria uma reportagem que esclarecendo essas dúvidas, o que não chega a acontecer. Pelo contrário, os próprios jornalistas não sabiam ao certo como se calculava o preço de varejo dos discos, e nem sequer artistas renomados sabiam responder essas questões. Mesmo as gravadoras caiam em um mar de contradições quando tentavam esclarecer os aumentos constantes do preço dos álbuns.

Isso não significa que não houve tentativas de se baratear o preço final dos álbuns. Uma dessas experiências consistia em baixar o custo de produção, fazendo álbuns com menos músicas, lançando discos de dez polegadas, ao invés das tradicionais doze polegadas dos discos standard. A lógica era simples: com duas polegadas a menos, seria utilizada uma quantidade menor de resina derivada do petróleo, e o fato de caber menos músicas em um disco menor era outro fator que levaria a seu barateamento.

Num disco menor cabem menos faixas. Menor número de faixas exige menor tempo de estúdio. Menor tempo de estúdio representa também um número menor de horas pagas aos músicos para gravar. E mais: um disco menor tem capa menor, reduzindo, portanto, o custo gráfico do produto final. Ou seja: economia por todos os lados. ${ }^{28}$

Entretanto, havia uma falha no plano das gravadoras em lançar discos de menor dimensão, pois tais álbuns ficariam perdidos nas gôndolas e estantes das lojas, passando despercebidos. E não apenas isso: o argumento de que um menor tempo de estúdio representaria um disco mais barato é desmentido pela célebre cantora Elis Regina, destacando uma falta de lógica no preço de varejo dos discos.

Meu último disco foi gravado apenas em 15 dias, enquanto o comum são dois ou três meses de trabalho, e Falso Brilhante foi gravado apenas em dois dias. E nem por isso as gravadoras

27 MENDES, Arthur. Cartas. Revista SOMTRÊS, São Paulo, n. 09, set. 1979, p. 04.

${ }^{28}$ KUBRUSLY, Maurício. A crise em 33 RPM. Revista SOMTRÊS, São Paulo, n. 27, mar. 1981, pp. 96.

João Pessoa - Brasil

ANO 7 VOL.7 N.1 | JAN./JUN. 2020 | p. 434-453 


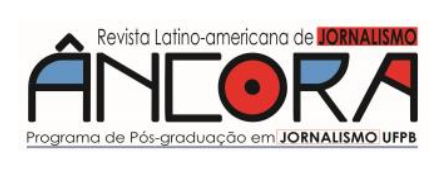

Enio Everton A. VIEIRA

venderam esses discos a preços mais reduzidos. O certo é que o preço do disco no Brasil é absolutamente louco. ${ }^{29}$

Elis não compreende que sua música estava inserida em um contexto de produção industrial, organizada nos moldes do mais racional planejamento, submetida a uma verdadeira linha de montagem (DIAS, 2008, p. 20). Nesse sentido, o preço dos álbuns vendidos era calculado segundo a média de mercado, com discos que tiveram um custo de produção mais caros compensados pelo custo de álbuns gravados em poucos dias, não importando o tamanho das canções e/ou os arranjos feitos. Há uma padronização da música enquanto obra de arte, dando ao consumidor uma aparência de escolha, quando, em realidade, todos os ouvintes acabam por consumir apenas mais um produto industrializado da sociedade de consumo.

Na busca por culpados pela crise da indústria fonográfica, é claro que as rádios e a pirataria seriam mencionadas. Se os audiófilos elogiavam a postura de estações de FM que tocavam discos inteiros em suas programações, os homens de negócio das gravadoras se queixavam que essa postura estava simplesmente "massacrando a venda dos discos"30. As estações de rádio tocavam "discos inteiros, sem qualquer interrupção - ou até convocando os ouvintes para a gravação, dando um sinal característico antes do início e depois do fim da faixa a ser gravada" ${ }^{31}$. Se sugeriu, inclusive, a cobrança de "uma taxa na compra de equipamentos reprodutores e também de cada fita cassete virgem. Esta taxa seria revertida para a área dos direitos do autor e do produtor, como já [era] feito em diversos países da Europa"32.

E de fato, no final dos anos oitenta, os impostos sobre fitas em branco estavam em vigor em alguns países, como França, Alemanha, Holanda, Portugal e Espanha (HEYLIN, 1994, p. 241). Essa taxa era considerada uma

\footnotetext{
${ }^{29}$ Depoimento de Elis Regina dado em reportagem de LIMA, Walmir M. de. Eonde está o culpado?Revista SOMTRÊS, São Paulo, n. 32, ago. de 1981, pp. 99-102.

30 Depoimento de Hans Paul Beugger, superintendente geral da gravadora Continental, em reportagem de LIMA, Walmir M. de. E onde está o culpado? Revista SOMTRÊS, São Paulo, n. 32, ago. 1981, p. 100. 31 LIMA, Walmir M. de. E onde está o culpado? Revista SOMTRÊS, São Paulo, n. 32, ago. 1981, p. 100.

32 Depoimento de Hans Paul Beugger, superintendente geral da gravadora Continental, em reportagem de LIMA, Walmir M. de. E onde está o culpado? Revista SOMTRÊS, São Paulo, n. 32, ago. 1981, p. 100.
} 
medida compensatória por parte das gravadoras, buscando desencorajar a compra de fitas cassetes virgens por usuários ávidos para efetuar gravações caseiras, sendo "um meio de extorquir dinheiro de todos os usuários de fitas virgens para pagar por supostas violações de direitos autorais" (HEYLIN, 1994, p. 212). Clinton Heylin acusa essas taxas de extorsivas, pelo fato que de que tal taxa não funcionaria como um sistema tradicional de pagamento de direito autoral. Afinal, como pagar os direitos de algo inexistente, no caso de uma fita virgem? O dinheiro geral iria direto para as gravadoras, e não para os artistas, levando as gravadoras a lucrarem cerca de 70-80 milhões de libras (isso apenas no Reino Unido), e teve como consequência um aumento de $100 \%$ no preço das fitas cassete (HEYLIN, 1994, p. 238).

Por fim, membros da própria classe artística admitiam que viviam em um momento de crise de criatividade. Se havia no Brasil todavia existia a censura, que em sua atuação "afastou vários artistas que poderiam ter renovado a música brasileira"33, Elis Regina destaca um comodismo e uma suposta falta de diversidade por parte dos artistas nacionais do período.

A maioria dos artistas está gravando o mesmo compositor, acompanhada pelos mesmos músicos, com arranjos feitos por um único arranjador, praticamente no mesmo gênero. Em consequência, se são oferecidos cinco LPs ao consumidor, não há necessidade dele comprar os cinco, para ouvir a mesma música em todos os cinco. Basta comprar um só. ${ }^{34}$

Essa suposta falta de criatividade no mercado de música brasileira já havia sido apontada na própria revista por Kubrusly pela "inexistência de uma [nova] grande moda, como os Beatles, como o rock. É verdade, uma onda qualquer sempre empurra as vendas para cima" ${ }^{\prime \prime 3}$. Com o fim da moda da discoteca, ainda se passariam alguns anos até a explosão do rock made in

33 Depoimento de Hans Paul Beugger, superintendente geral da gravadora Continental, em reportagem de LIMA, Walmir M. de. E onde está o culpado? Revista SOMTRÊS, São Paulo, n. 32, ago. 1981, p. 101. ${ }^{34}$ Depoimento dado em reportagem de LIMA, Walmir M. de. E onde está o culpado? Revista SOMTRÊS, São Paulo, n. 32, ago. 1981, pp. 99-102.

35 KUBRUSLY, Maurício. A crise em 33 RPM. Revista SOMTRÊS, São Paulo, n. 27, mar.1981, p. 96.

João Pessoa - Brasil | ANO 7 VOL.7 N.1 | JAN./JUN. 2020 | p. 434-453 
musical, fizeram as vendas de discos caírem vertiginosamente. O Brasil caiu de quinto maior mercado mundial de discos para o sétimo lugar, o que foi visto como um possível fim da indústria musical, discurso exagerado que se reproduz nos dias atuais, ainda mais em tempos de música gratuita, feito possibilitado pela popularização da internet e da tecnologia streaming.

\section{Referências}

BAUMAN, Zygmunt. Vida para consumo: a transformação das pessoas em mercadoria. Rio de Janeiro: Zahar, 2008.

BENJAMIN, Walter. La obra de arte en la época de su reproductibilidad técnica. Editorial Itaca. México, D. F., 2003.

COGGIOLA, Osvaldo. A Revolução Iraniana. Editora Unesp, 2008. DIAS, Marcia Tosta. Os donos da voz: indústria fonográfica brasileira e mundialização da cultura. São Paulo: Boitempo, 2008.

FAUSTO, Boris. História do Brasil. São Paulo: Editora da Universidade de São Paulo, 2012.

FRIEDLANDER, Paul. Rock and roll: uma história social. Rio de Janeiro: Record, 2012.

HEYLIN, Clinton. Bootleg: the secret history of the other recording industry. New York: St. Martin's Press, 1994.

LADEIRA, Alexandre Gouvêa. O bom gosto pelas margens: motivações sociais no consumo de produtos piratas. Tese de Doutorado. Faculdade de Filosofia e Ciências Humanas da Universidade Federal de Minas Gerais: Belo Horizonte: 2013.

LOSSO, Fábio Malina. Os Direitos Autorais no Mundo da Música. Tese de Doutorado. Faculdade de Direito da Universidade de São Paulo: São Paulo. 2008.

MELLO, João Manuel Cardoso de, e NOVAIS, Fernando A. Capitalismo Tardio e Sociabilidade Moderna. In: História da Vida Privada no Brasil (vol. 4): contrastes da intimidade contemporânea. SCHWARCZ, Lilia Moritz (Org.). São Paulo: Companhia das Letras, 1998.

NAPOLITANO, Marcos. 1964: História do Regime Militar Brasileiro. São

Paulo: Contexto, 2014.

ORTIZ, Renato. Mundialização e cultura. São Paulo: Brasiliense, 2003. SANTOS, Christiano Rangel dos. Pirataria musical: entre o ilícito e 0 alternativo. Dissertação de Mestrado. Universidade Federal de Uberlândia: Uberlândia, 2010.

SEVERIANO, Jairo. Uma história da música popular brasileira: das origens à modernidade. São Paulo: Ed. 34, 2008.

SILVA, Francisco Carlos Teixeira da. Crise da ditadura militar e processo de abertura política no Brasil, 1974-1985. In: O Brasil Republicano, vol. 4. O

João Pessoa - Brasil | ANO 7 VOL.7 N.1 | JAN./JUN. 2020 | p. 434-453 


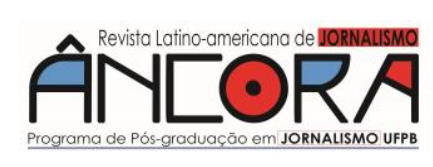

Enio Everton A. VIEIRA

tempo da ditadura: regime militar e movimentos sociais em fins do século XX. Jorge Ferreira e Lucilia de Almeida Neves (Orgs). Rio de Janeiro:

Civilização Brasil, 2013.

TINHORÃO, José Ramos. Cultura popular: temas e questões. São Paulo: Ed. 34, 2001.

\section{Fontes primárias}

Revista SOMTRÊS, São Paulo, n. 01, jan. 1979.

Revista SOMTRÊS, São Paulo, n. 03, mar. 1979.

Revista SOMTRÊS, São Paulo, n. 09, set. 1979.

Revista SOMTRÊS, São Paulo, n. 13, jan. 1980.

Revista SOMTRẾS, São Paulo, n. 14, fev. 1980.

Revista SOMTRÊS, São Paulo, n. 15, mar. 1980.

Revista SOMTRÊS, São Paulo, n. 16, abr. 1980.

Revista SOMTRÊS, São Paulo, n. 17, mai. 1980.

Revista SOMTRÊS, São Paulo, n. 18, jun. 1980.

Revista SOMTRÊS, São Paulo, n. 19, jul. 1980.

Revista SOMTRÊS, São Paulo, n. 20, ago. 1980.

Revista SOMTRÊS, São Paulo, n. 21, set. 1980.

Revista SOMTRÊS, São Paulo, n. 22, out. 1980.

Revista SOMTRÊS, São Paulo, n. 23, nov. 1980.

Revista SOMTRẾS, São Paulo, n. 24, dez. 1980.

Revista SOMTRÊS, São Paulo, n. 25, jan. 1981.

Revista SOMTRÊS, São Paulo, n. 26, fev. 1981.

Revista SOMTRÊS, São Paulo, n. 27, mar. 1981.

Revista SOMTRÊS, São Paulo, n. 28, abr. 1981.

Revista SOMTRÊS, São Paulo, n. 29, mai. 1981.

Revista SOMTRÊS, São Paulo, n. 30, jun. 1981.

Revista SOMTRÊS, São Paulo, n.31, jul. 1981.

Revista SOMTRÊS, São Paulo, n. 32, ago. 1981.

Revista SOMTRÊS, São Paulo, n. 33, set. 1981.

Revista SOMTRÊS, São Paulo, n.34, out. 1981.

Revista SOMTRÊS, São Paulo, n. 35, nov. 1981.

Revista SOMTRÊS, São Paulo, n. 36, dez. 1981.

As revistas utilizadas para esta pesquisa pertencem ao acervo da Sala Sérgio Milliet. Biblioteca Mário de Andrade, São Paulo, SP. 